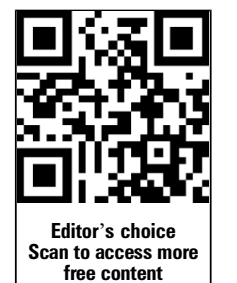

free content

- Additional material is published online only. To view please visit the journal online (http://dx.doi.org/10.1136/ bjsports-2013-092165).

${ }^{1}$ The Swedish School of Sport and Health Sciences, Stockholm, Sweden

${ }^{2}$ The Section of Orthopaedics and Sports Medicine, Department of Molecular Medicine and Surgery, Karolinska Institutet, Stockholm, Sweden ${ }^{3}$ Department of Radiology, Karolinska Sjukhuset, Stockholm, Sweden

Correspondence to Dr Carl M Askling, GIH, Box 5626, 11486 Stockholm, Sweden, carl.askling@gih.se

Accepted 26 February 2013 Published Online First 27 March 2013
To cite: Askling $\mathrm{CM}_{\text {, }}$ Tengvar M, Thorstensson A. Br J Sports Med 2013;47:953-959.

\title{
Acute hamstring injuries in Swedish elite football: a prospective randomised controlled clinical trial comparing two rehabilitation protocols
}

\author{
Carl M Askling, ${ }^{1,2}$ Magnus Tengvar, ${ }^{3}$ Alf Thorstensson ${ }^{1}$
}

\begin{abstract}
Background Hamstring injury is the single most common injury in European professional football and, therefore, time to return and secondary prevention are of particular concern.

Objective To compare the effectiveness of two rehabilitation protocols after acute hamstring injury in Swedish elite football players by evaluating time needed to return to full participation in football team-training and availability for match selection.
\end{abstract}

Study design Prospective randomised comparison of two rehabilitation protocols.

Methods Seventy-five football players with an acute hamstring injury, verified by MRI, were randomly assigned to one of two rehabilitation protocols. Thirtyseven players were assigned to a protocol emphasising lengthening exercises, L-protocol and 38 players to a protocol consisting of conventional exercises, C-protocol. The outcome measure was the number of days to return to full-team training and availability for match selection. Reinjuries were registered during a period of 12 months after return.

Results Time to return was significantly shorter for the players in the L-protocol, mean 28 days $(1 S D \pm 15$, range 8-58 days), compared with the C-protocol, mean 51 days ( $1 S \mathrm{SD} \pm 21$, range $12-94$ days). Irrespective of protocol, stretching-type of hamstring injury took significantly longer time to return than sprinting-type, L-protocol: mean 43 vs 23 days and C-protocol: mean 74 vs 41 days, respectively. The L-protocol was significantly more effective than the C-protocol in both injury types. One reinjury was registered, in the C-protocol.

Conclusions A rehabilitation protocol emphasising lengthening type of exercises is more effective than a protocol containing conventional exercises in promoting time to return in Swedish elite football.

\section{INTRODUCTION}

Hamstring injury is the single most common injury in elite football. ${ }^{1} 2$ This means that a professional male football team with 25 players would suffer about five hamstring injuries each season, equivalent to more than 80 lost football days. ${ }^{1}$ Furthermore, hamstring injuries are a heterogeneous group consisting of different injury types, locations and sizes, which makes recommendations regarding rehabilitation and prognosis about healing time difficult. ${ }^{3-7}$ The reinjury rate in football is high ${ }^{189}$ which, in most cases, probably indicates inadequate rehabilitation programmes and/or premature return to football. ${ }^{10-12}$
There is a lack of clinical research and consensus regarding the effectiveness of various rehabilitation protocols for acute hamstring injuries in football. The primary objective of all rehabilitation protocols is to return the player as soon as possible to the prior level of performance with a minimal risk of injury recurrence. Few studies to date have evaluated the effectiveness of different treatment protocols for acute hamstring injuries in athletes. ${ }^{10}$ To our knowledge, there are no prospective, randomised studies in the literature investigating the effectiveness of different rehabilitation protocols in elite football.

It has been suggested that hamstring exercises being performed at longer muscle-tendon length, preferentially mimicking movements occurring simultaneously at both the knee and the hip, could be a key strategy in the management of hamstring injuries. ${ }^{13} 14$

\section{Aim}

The main objective of this study on Swedish elite football players was to compare the effectiveness of two rehabilitation protocols for acute hamstring injuries with varying emphasis on muscle-tendon lengths by evaluating time needed to return to full participation in football team training and availability for match selection. Other aims were to study possible correlations between injury type, location, size, palpation pain and time to return.

\section{MATERIAL AND METHODS}

Male as well as female players were recruited using our extensive contacts with medical teams working with elite football in Sweden. The total recruitment time was 33 months, January 2009-September 2011. Seventy-five players, mainly from the two highest divisions, were included in the study, all with clinical signs of acute hamstring injury, which were confirmed by MRI. A randomisation process was used to assign the players to either of the two protocols, the L-protocol or the C-protocol, respectively. Stratification was carried out for gender and injury-type, that is, sprinting-type or stretching-type of injury (see below). In addition, 11 players with clinical signs of acute hamstring injury, but where the MRI showed no sign of injury, were followed in parallel. These MRI-negative players were all assigned to the L-protocol. All players gave their informed consent prior to their participation. Approval of the study was granted from the Regional Ethics Committee (Dnr: 2008/1320-31/2). There were no drop-outs in the study. 


\section{Inclusion/exclusion criteria}

To be included, the player had to have had an acute sudden pain in the posterior thigh when training football or playing a match. The initial clinical examination had to reveal localised pain when palpating the hamstring muscles, localised pain while performing a passive straight leg raise test and increased pain when adding an isometric hamstring contraction during that test. ${ }^{3}$ Exclusion criteria included verified or even suspected, earlier hamstring injuries in the same leg during the last 6 months, extrinsic trauma to the posterior thigh, ongoing or chronic lower back problems and pregnancy.

\section{Injury situation-type of injury}

At the first visit, the players were interviewed about the injury situation, that is, the movements or exercises during which the acute injury occurred. As the majority of the players came from the two highest football divisions in Sweden, video clips of the injury situation were available in many cases (46 of 75). The video was used to confirm if the injury was a sprinting-type injury, that is, occurred at high-speed running and/or acceleration or a stretching-type injury, that is, occurred during movements with large joint excursions, that is, high kicking, split positions and glide tackling.

\section{Clinical examination}

All players were examined within 2 days after the injury. The clinical examination included manual assessment of flexibility and strength of the injured and uninjured legs. The point of peak palpation pain was recorded and the distance between that point and the ischial tuberosity was measured. ${ }^{3}$ The same test-leader (CMA) performed this clinical examination weekly until there were no signs of remaining injury. The last decision by the CMA had to be confirmed by an independent colleague before being finalised.

\section{Askling H-test}

When the clinical examination showed no signs of remaining injury, the Askling H-test was performed. ${ }^{15}$ If the player experienced insecurity during this dynamic test, he/she was not allowed to go back to full team training and/or match. Instead, the rehabilitation period was extended and the H-test repeated with an interval of 3-5 days until insecurity was eliminated.

\section{MRI}

All players underwent an MRI investigation within 5 days after the acute injury. MRI investigations were performed on a 1.5 Tesla superconductive MRI unit (Magnetom Symphony, Siemens, Erlangen, Germany). Briefly, longitudinal, sagittal and frontal short tau inversion recovery (STIR) images as well as transversal T1-weighted and STIR images $(5 \mathrm{~mm}$ slice thickness and $0.5 \mathrm{~mm}$ gap) were obtained from both legs. ${ }^{4}$ A muscle was considered injured when it contained high signal intensity (oedema) on the STIR images, as compared with that of the uninjured side. If more than one muscle/tendon was injured, the one with the greatest signal abnormality was considered the 'primary' injury and the second largest, the 'secondary' injury. In this study, MRI parameters were quantified only for the primary injury. The free proximal tendon (PT) was deemed injured if two of the three following parameters were present: the tendon was thickened, and/or had a collar of high signal intensity around it and/or had high intratendinous signal intensity, as compared with the uninjured side. The maximal longitudinal length of the muscle/tendon oedema was measured. ${ }^{4}$ In addition, the perpendicular distance between the level of the most proximal pole of the oedema and the level of the most distal part of the ischial tuberosity was measured. ${ }^{4}$

\section{Rehabilitation protocols}

The time from the date of injury to the date of rehabilitation protocol initiation was 5 days for both protocols. Overall, exercises were chosen that could be performed in any place and without the use of advanced equipment. The exercises of the L-protocol specifically aimed at loading the hamstrings during extensive lengthening, mainly during eccentric muscle actions. In contrast, the C-protocol consisted of conventional exercises for the hamstrings with less emphasis on lengthening. Each rehabilitation protocol consisted of three different exercises, where exercise 1 was aimed mainly at increasing flexibility, exercise 2 was a combined exercise for strength and trunk/pelvis stabilisation and exercise 3 was more of a specific strength training exercise. All exercises were performed in the sagittal plane. The intensity and volume of training were made as equal as possible between the two protocols. The training sessions were supervised, at least once every week, during the whole rehabilitation period, and the speed and load were increased over time. No pain provocation was allowed at any time when performing the exercises. All exercises included in the two rehabilitation protocols are explained in figures 1-6 and shown in online supplementary videos $1-6$.

\section{Outcome}

The main outcome is time to return, that is, time needed from the incidence of injury to full participation in football team training and availability for match selection. Also occurrence of reinjuries was registered during a 12 months period after return. If a reinjury occurred, the responsible medical team was to immediately contact the study leader so that the same procedure as for the original injury could be repeated. The full 1-year follow-up period was completed by all players in the study.

\section{Statistical analyses}

All statistical analyses were conducted with SPSS V.19.0 software (SPSS Inc, Chicago, Illinois, USA). Shapiro-Wilk W tests showed that the data were not normally distributed. The Mann-Whitney $\mathrm{U}$ test was performed to investigate differences in age, height and mass as well as MRI and palpation measures. A $\chi^{2}$ test was applied to investigate differences in proportions of injury type

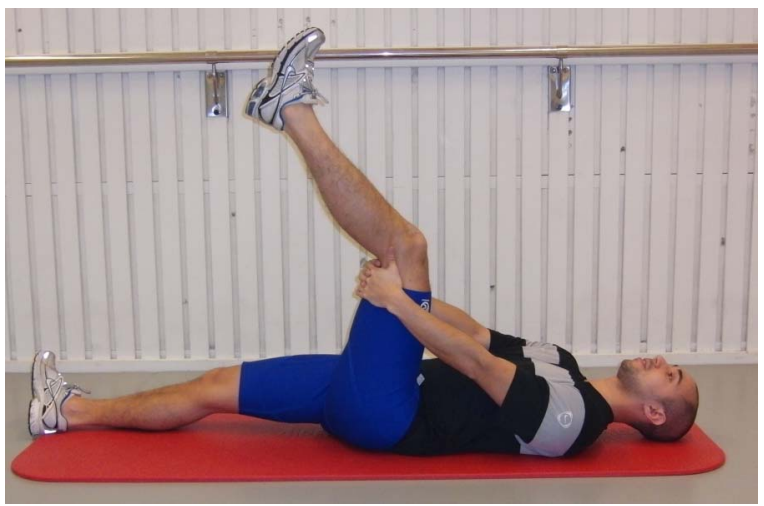

Figure $1 \quad L-1$ 'The Extender'. The player should hold and stabilise the thigh of the injured leg with the hip flexed approximately $90^{\circ}$ and then perform slow knee extensions to a point just before pain is felt. Twice every day, three sets with 12 repetitions (online supplementary video 1). Access the article online to view this figure in colour. 


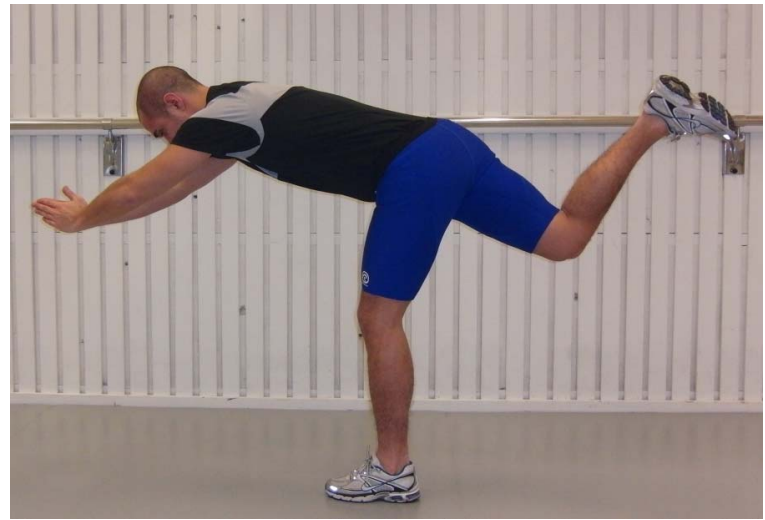

Figure 2 L-2 'The Diver'. The exercise should be performed as a simulated dive, that is, as a hip flexion (from an upright trunk position) of the injured, standing leg and simultaneous stretching of the arms forward and attempting maximal hip extension of the lifted leg while keeping the pelvis horizontal; angles at the knee should be maintained at $10-20^{\circ}$ in the standing leg and at $90^{\circ}$ in the lifted leg. Owing to its complexity, this exercise should be performed very slowly in the beginning. Once every other day, three sets with six repetitions (online supplementary video 2). Access the article online to view this figure in colour.

and PT involvement as well as in gender and level of performance. The Mann-Whitney U test was also used to assess differences in time to return between the protocols, between subgroups with respect to injury type and PT involvement, as well as between MRI-negative players and players with sprinting-type injury within the L-protocol. Spearman rank order correlations were calculated to investigate associations between time to return and MRI and palpation parameters. The significance level was set at $\mathrm{p} \leq 0.05$.

\section{RESULTS}

\section{Injury type and location}

Fifty-four (72\%) of all 75 MRI-verified hamstring injuries were sprinting-type and 21 (28\%) were stretching-type injuries. In 52

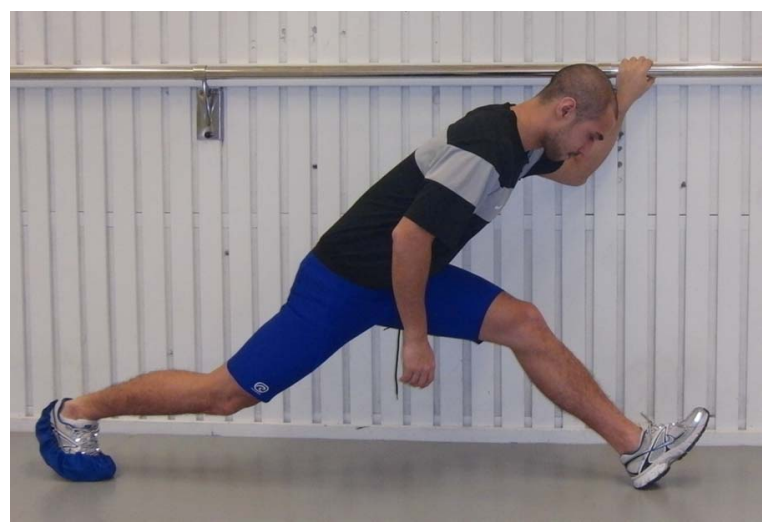

Figure 3 L-3 'The Glider'. The exercise is started from a position with upright trunk, one hand holding on to a support and legs slightly split. All the body weight should be on the heel of the injured (here left) leg with approximately $10-20^{\circ}$ flexion in the knee. The motion is started by gliding backward on the other leg (note low friction sock) and stopped before pain is reached. The movement back to the starting position should be performed by the help of both arms, not using the injured leg. Progression is achieved by increasing the gliding distance and performing the exercise faster. Once every third day, three sets with four repetitions (online supplementary video 3 ). Access the article online to view this figure in colour.

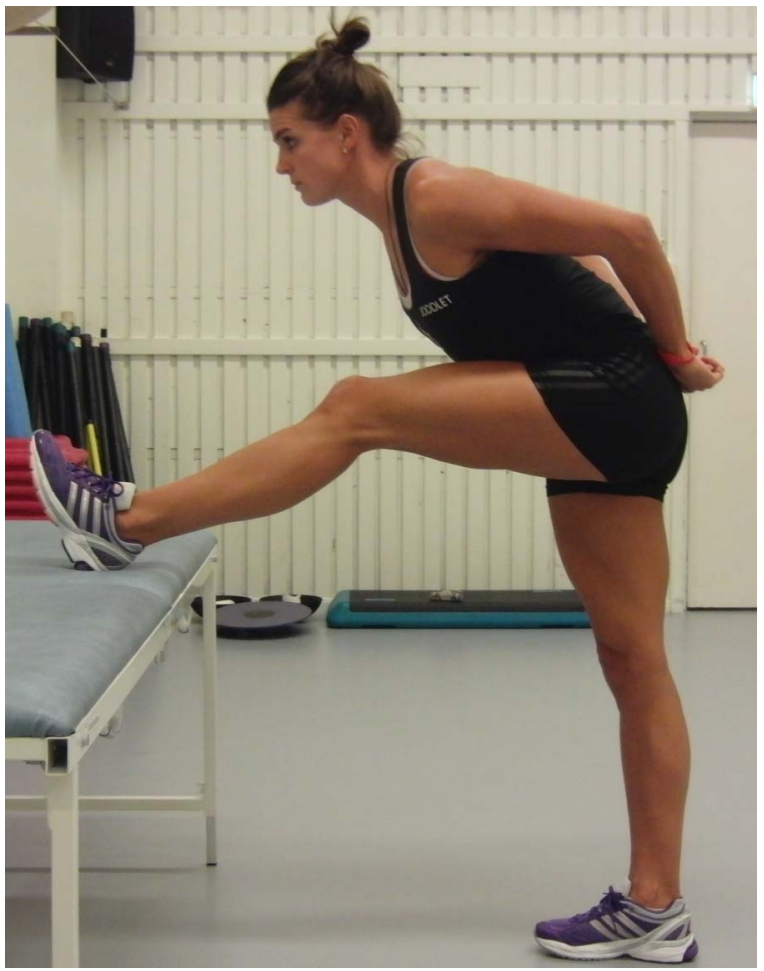

Figure 4 C-1 Stretching-contract/relax. The heel of the injured leg is placed on a stable support surface in a high position (close to maximum) with the knee in approximately $10^{\circ}$ flexion. The heel is pressed down for $10 \mathrm{~s}$ and then, after relaxation for $10 \mathrm{~s}$, a new position is assumed by flexing the upper body slowly forward for $20 \mathrm{~s}$. Twice every day, three sets with four repetitions (online supplementary video 4). Access the article online to view this figure in colour.

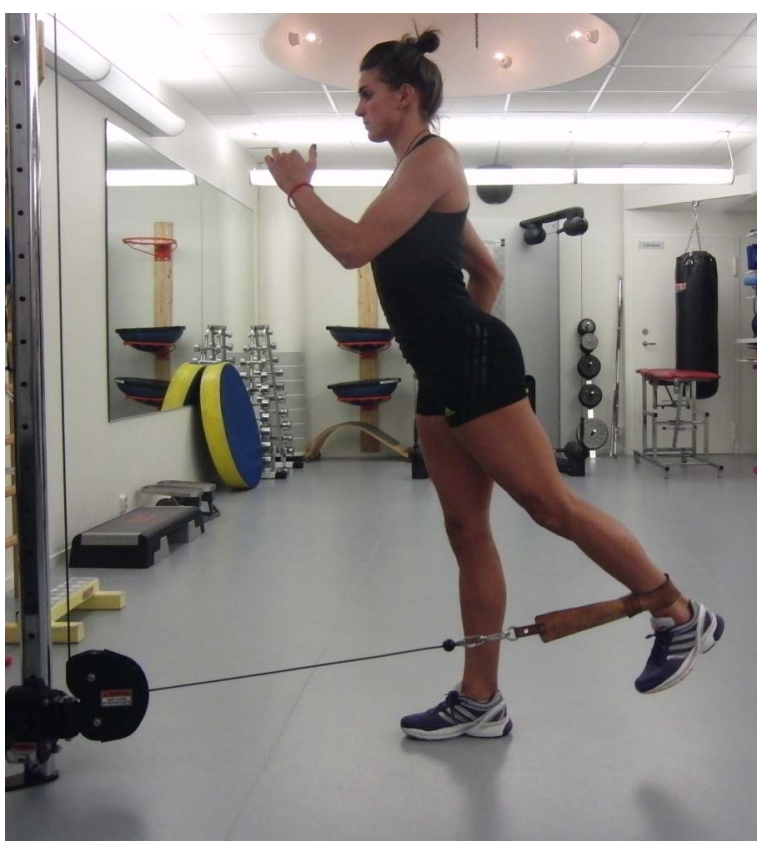

Figure 5 C-2 Cable-pendulum. A stationary cable-machine or expander is used. With the uninjured leg as standing leg, forward-backward hip motions are performed with the injured leg with the knee in approximately $20-30^{\circ}$ flexion. This exercise involves the whole body and should be performed slowly in the beginning of the rehabilitation period. Once every other day, three sets with six repetitions (online supplementary video 5). Access the article online to view this figure in colour. 


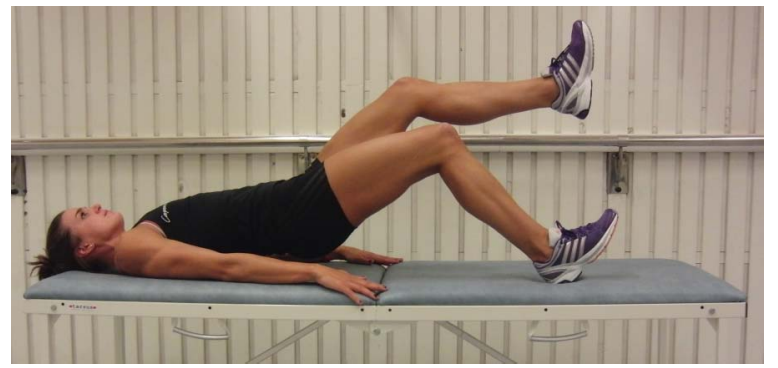

Figure 6 C-3 Pelvic lift. This exercise is started in a supine position with the body weight on both heels and then the pelvis is lifted up and down slowly. Start with the knee in $90^{\circ}$ of flexion. The load is increased by putting more of the body weight on the injured leg and by having a greater extension in the knee. Ultimately, only the slightly bent injured leg is carrying the load. Every third day, three sets with eight repetitions (online supplementary video 6). Access the article online to view this figure in colour.

of the 75 players (69\%), the primary injury was located in the long head of biceps femoris (BFlh) and in 25 of those 52 (48\%) there was a secondary injury commonly $(80 \%)$ located in the semitendinosus (ST). In 16 of the 75 players (21\%), the primary injury was located in semimembranosus (SM) and in 7 of those $16(44 \%)$ there was a secondary injury. A clear majority (94\%) of the primary injuries of sprinting-type was located in the BFlh, whereas SM was the most common (76\%) location for the stretching-type injury.

\section{Characterisation of protocol participants}

There were no significant differences between the groups of players in the L-protocol and the C-protocol with respect to the age, height, mass, gender, performance level, type of injury, involvement of proximal free tendon (table 1). Neither were there any differences in distance between the most proximal pole of the oedema and the ischial tuberosity, length of the oedema and distance between the point of peak palpation pain and the ischial tuberosity (table 1).

\section{Askling H-test}

Thirteen players (35\%) in the L-protocol and 27 in the C-protocol $(71 \%)$ experienced insecurity while performing the test and therefore needed to extend the rehabilitation period. In mean, the rehabilitation period was prolonged by 7 days $(1 \mathrm{SD} \pm 2.7$, range $3-14)$. On average, the rehabilitation period was prolonged by 7.5 days $(1 \mathrm{SD} \pm 2.8$, range $3-12)$ and 6.7 days $(1 \mathrm{SD} \pm 2.7$, range $3-14)$ in the L-protocol and C-protocol, respectively.

\section{Time to return}

Time to return was significantly shorter in the L-protocol compared with the C-protocol, mean 28 days $(1 \mathrm{SD} \pm 15$, range 8-58 days) and 51 days ( $1 S D \pm 21$, range $12-94$ days), respectively (figure 7). Time to return was also significantly shorter in the L-protocol than in the C-protocol for injuries of both sprinting-type and stretching-type (figure 8), as well as for injuries not involving and involving the PT (figure 9). The sprintingtype of injuries, per se, showed significantly shorter time to return compared with stretching-type injuries (figure 8). Also, injuries not involving PT showed significantly shorter time to return than those involving the PT (figure 9). Correlation analysis showed that the shorter the distance to tuber was from the most proximal pole of the injury measured by MRI or peak palpation pain, the longer the time was to return (table 2). A longer length of the oedema was also correlated with a significantly longer time to return (table 2).

\section{Reinjuries}

There was one reinjury registered during the 12-month follow-up period. This reinjury occurred in the C-protocol 6 months after the initial injury. Both injuries were of sprintingtype and located in the BFlh. The reinjury took 12 days to return compared with 16 days for the initial injury.

\section{MRI-negative group}

All of the injuries in the MRI-negative group were of sprintingtype. The characteristics of the MRI-negative group were similar to the corresponding group of players with sprint injuries in the L-protocol (table 3). The MRI negative group had significantly shorter time to return, mean 6 days ( $1 S D \pm 3$, range 3-14 days), than the corresponding group of players, that is, the sprintingtype of injuries within the L-protocol, mean 23 days $(1 \mathrm{SD} \pm 11$, range 8-44 days; figure 10).

\section{DISUSSION}

Outcome-time to return

The time to return to full training and match selection availability in elite football players after acute hamstring injury can be considerably affected by the choice of rehabilitation protocol. In this study on Swedish elite football players, the average time to

Table 1 Descriptive, MRI and palpation data, as means \pm 1SD (median and range) or ratios (\%) for players in the L-protocol and the C-protocol, respectively

\begin{tabular}{|c|c|c|c|}
\hline & L-protocol $(n=37)$ & C-protocol $(n=38)$ & $p$ Value \\
\hline Age (years) & $25 \pm 5(24,16$ to 37$)$ & $25 \pm 6(25,15$ to 37$)$ & $0.738^{*}$ \\
\hline Height $(\mathrm{cm})$ & $180 \pm 5(180,170$ to 198$)$ & $181 \pm 7(180,160$ to 196$)$ & $0.278^{*}$ \\
\hline Mass (kg) & $77 \pm 6(76,64$ to 90$)$ & $79 \pm 10(78,50$ to 113$)$ & $0.310^{*}$ \\
\hline Female $(\%) /$ male $(\%)$ & $8 / 92$ & $8 / 92$ & $0.973^{* *}$ \\
\hline Elite $(\%) /$ non-elite $(\%)$ & $89 / 11$ & $90 / 10$ & $0.968^{* *}$ \\
\hline Sprinting-type (\%)/stretching-type (\%) & $73 / 27$ & $71 / 29$ & $0.853^{* *}$ \\
\hline Proximal free tendon (PT) not involved (\%)/PT involved (\%) & $68 / 32$ & $74 / 26$ & $0.561^{* *}$ \\
\hline Distance from proximal injury pole to tuber, $\mathrm{mm}$ & $60 \pm 72(40,-30$ to 240$)$ & $67 \pm 80(40,-40$ to 280$)$ & $0.738^{*}$ \\
\hline Injury length, mm & $176 \pm 99(190,30$ to 400$)$ & $169 \pm 78(180,15$ to 325$)$ & $0.865^{*}$ \\
\hline Peak palpation pain, distance to tuber, $\mathrm{cm}$ & $10 \pm 7(8,1$ to 26$)$ & $10 \pm 8(8,1$ to 32$)$ & $0.903^{*}$ \\
\hline
\end{tabular}

*Mann-Whitney U test.

${ }^{* *} \chi^{2}$ test. The level of significance was set at $p \leq 0.05$. 


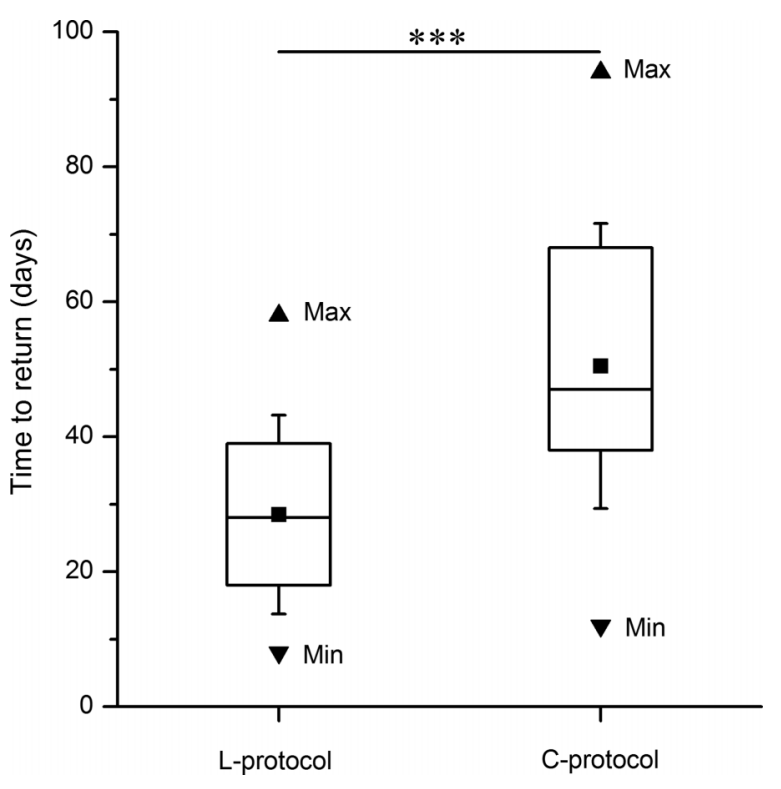

Figure 7 Time to return, in days, in either the L-protocol $(n=37)$ or C-protocol $(n=38)$. The boxes represent IQRs; in the boxes the horizontal lines represent median values and black squares represent mean values; whiskers $=$ mean $\pm 1 \mathrm{SD} .{ }^{* * *}$ Denotes significant difference $(p<0.001$, Mann-Whitney $U$ test).

return was shortened with 23 days, from 51 to 28 days (45\%) by replacing conventional exercises (C-protocol) with exercises emphasising loading of the hamstring muscles at lengths near the maximal (L-protocol). It should be noted that included in

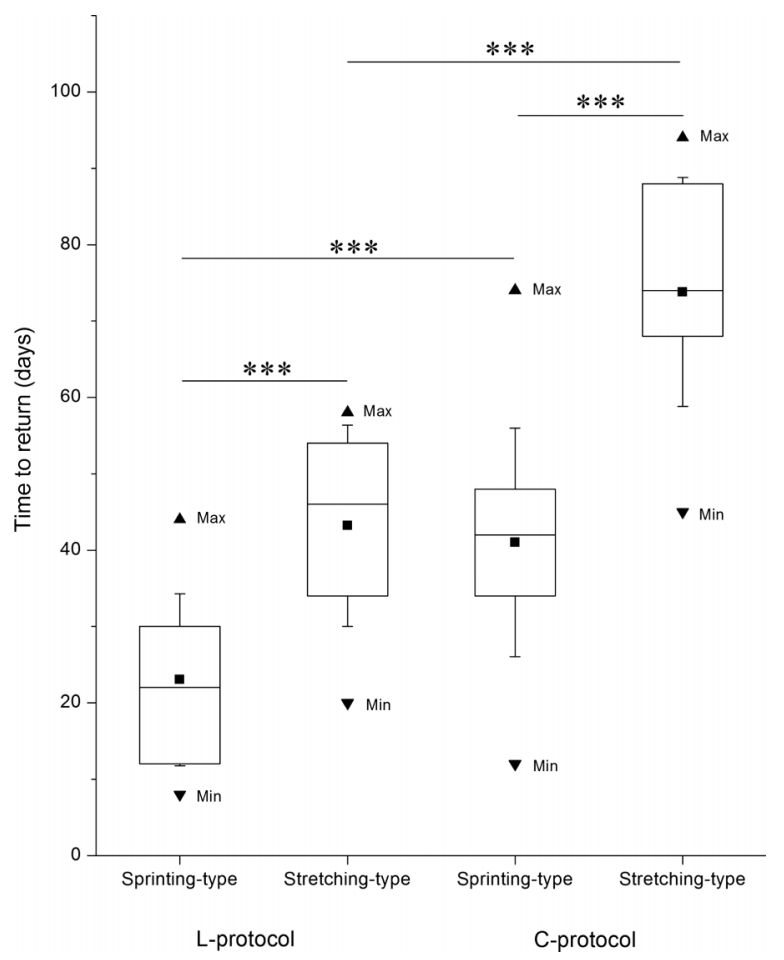

Figure 8 Time to return, in days, for players with either sprinting-type or stretching-type injuries in either the L-protocol $(n=27$ and 10, respectively) or C-protocol ( $n=27$ and 11, respectively). The boxes represent IQRs; in the boxes the horizontal lines represent median values and black squares represent mean values;

whiskers $=$ mean \pm 1 SD. ${ }^{* * *}$ Denotes significant difference $(p<0.001$, Mann-Whitney U test).

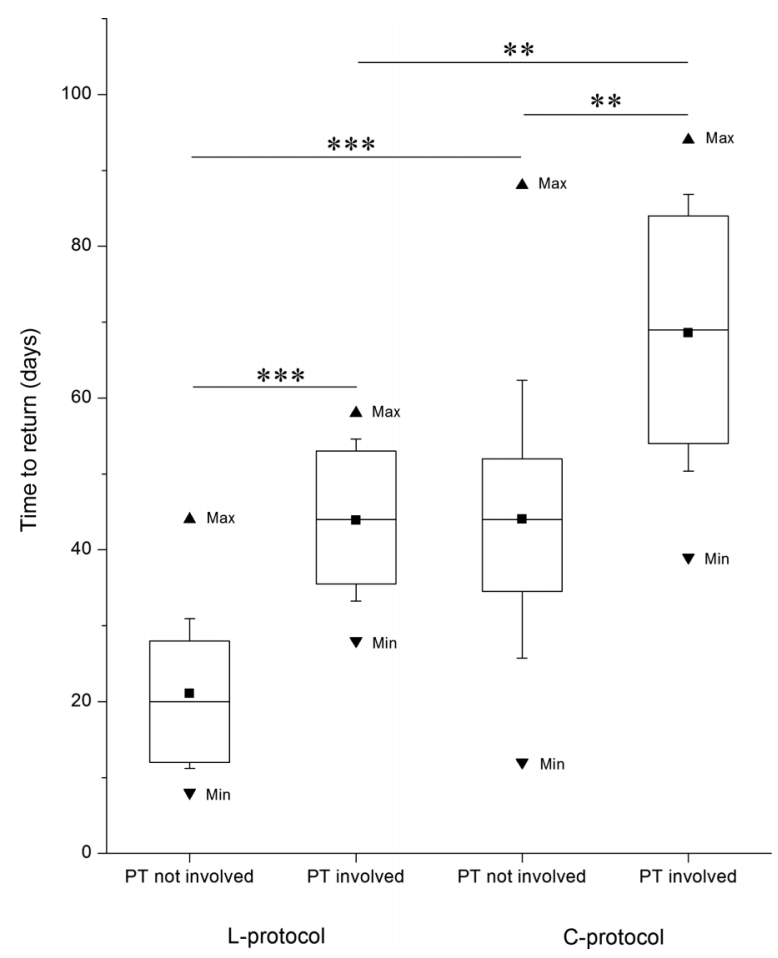

Figure 9 Time to return, in days, for players with injuries either involving or not involving the proximal free tendon (PT) in either the L-protocol ( $n=25$ and 12, respectively) or the C-protocol ( $n=28$ and 10, respectively). The boxes represent IQRs; in the boxes the horizontal lines represent median values and black squares represent mean values; whiskers $=$ mean \pm 1 SD. ${ }^{* *}=p<0.01 ;{ }^{* * *}=p<0.001$ denote significant differences (Mann-Whitney $U$ test).

these numbers are extra days caused by the inclusion of the extracriterion test, Askling $\mathrm{H}$-test. On average, the rehabilitation period was prolonged by 7 days $(1 \mathrm{SD} \pm 2.7$, range $3-14$ days). Without this extratest the time to return would have been shorter but the difference between the L-protocol and C-protocol would still have remained highly significant, mean 25 and 46 days, respectively. Since earlier similar intervention studies are lacking, no directly comparable numbers for times to return are available. As a comparison it can be mentioned that Petersen $e t a l^{9}$ in a hamstring injury prevention study of Danish elite and subelite football players, reported mean 'recovery times' of 30 (range 7-64 days) and 26 days (range 4-89 days).

\section{Exercise characteristics—possible differential effects between protocols}

The exercises in both protocols were selected based on practical experience and applied anatomy, not on biomechanical analysis.

Table 2 Correlations between time to return and MRI and palpation parameters in players in the L-protocol and C-protocol, respectively

\begin{tabular}{|c|c|c|c|c|}
\hline & \multicolumn{2}{|l|}{ L-protocol } & \multicolumn{2}{|l|}{ C-protocol } \\
\hline & Spearman's $r$ & $p$ Value & Spearman's r & $\mathrm{p}$ Value \\
\hline Distance to tuber (mm) & -0.736 & $<0.001$ & -0.717 & $<0.001$ \\
\hline Length (mm) & 0.817 & $<0.001$ & 0.320 & $<0.05$ \\
\hline Palpation $(\mathrm{cm})$ & -0.832 & $<0.001$ & -0.859 & $<0.001$ \\
\hline
\end{tabular}


Table 3 Descriptive data, as means \pm 1SD (median and range) or (\%) for players in the MRI-negative group and the sprinting-type injury within the L-protocol, respectively

\begin{tabular}{|c|c|c|c|}
\hline & MRI-negative $(n=11)$ & L-protocol ( $n=27)$ sprinting-type & p Value \\
\hline Age (years) & $23 \pm 7(21,15$ to 36$)$ & $25 \pm 5(26,16$ to 37$)$ & $0.302^{*}$ \\
\hline Height $(\mathrm{cm})$ & $181 \pm 6(179,174$ to 192$)$ & $180 \pm 4(179,170$ to 189$)$ & $0.961^{*}$ \\
\hline Mass (kg) & $75 \pm 7(76,60$ to 86$)$ & $77 \pm 6(76,64$ to 90$)$ & $0.759^{*}$ \\
\hline Female $(\%) /$ male $(\%)$ & $9 / 91$ & $11 / 89$ & $0.854^{* *}$ \\
\hline Sprinting-type (\%)/Stretching-type (\%) & $100 / 0$ & $100 / 0$ & \\
\hline Elite $(\%) /$ non-elite (\%) & $100 / 0$ & $96 / 4$ & \\
\hline
\end{tabular}

Lacking objective data we cannot pinpoint the factors causing the remarkable difference in outcome between the two protocols. The most conspicuous characteristics of the more successful L-protocol were the systematic attempts to put load on the hamstrings during maximal dynamic lengthening, the latter involving movements at both the hip and the knee. The contribution of eccentric actions might also have been greater in the L-programme, although we have no data to directly support such a statement. Otherwise, the two protocols were made as similar as possible in terms of early start after injury, thorough instruction and regular follow-up and progression in load/speed/ excursion based on the avoidance of the pain criterion.

The selection of these properties of the L-protocol was based on the common assumption of specificity, that is, the rehabilitation training, within reasonable limits, should attempt to mirror the particular situation that lead to the injury. Even though the exact mechanisms behind different types of hamstring injuries are unknown, several pieces of indirect evidence point to the aforementioned factors to be important ${ }^{14} 16$ and several authors have suggested that rehabilitating acute hamstring injuries

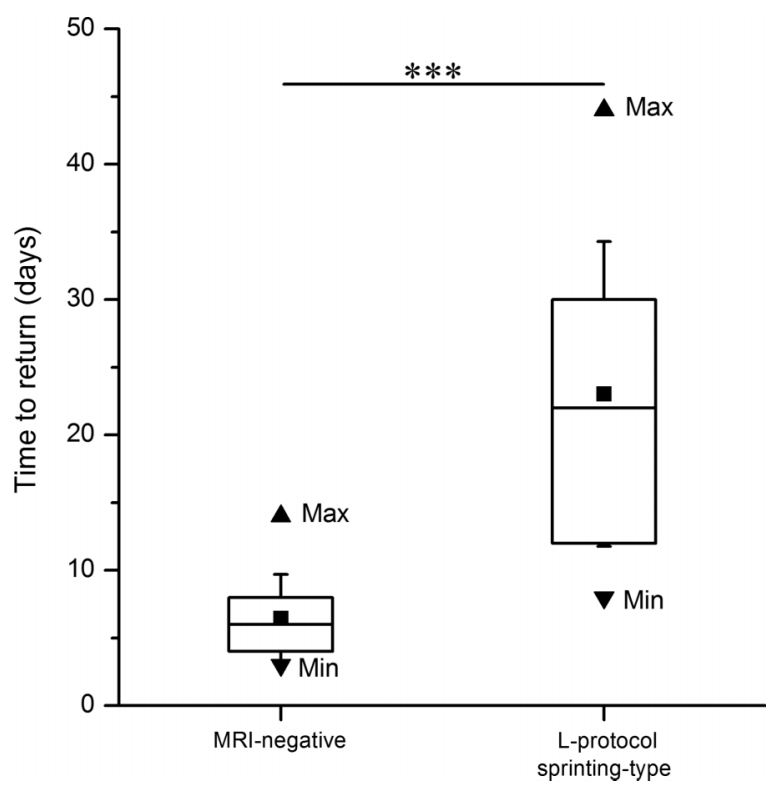

Figure 10 Time to return, in days, for MRI-negative players $(n=11$, all performing L-protocol) or for players with sprinting-type injuries within the L-protocol $(n=27)$. The boxes represent IQRs; in the boxes the horizontal lines represent median values and black squares represent mean values; whiskers $=$ mean $\pm 1 \mathrm{SD} .{ }^{* *}$ Denotes significant difference $(p<0.001$, Mann-Whitney U test). should build on attaining eccentric loading at as long muscle lengths as possible. ${ }^{17-19}$

\section{Factors predicting time to return irrespective of rehabilitation protocol}

Earlier investigations of ours have identified two main types of acute hamstring injuries, one occurring at high-speed running, typical for sprinters ${ }^{4}$ the other occurring during slow stretching to extreme muscle lengths, typical for dancers ${ }^{5}$ but also occurring in other athletes. ${ }^{6}$ These types of injuries are best distinguished by identifying these typical injury situations, either relying on players' report or on other forms of documentation, for example, videos from elite football matches as used here. Ekstrand $\mathrm{et} \mathrm{al}^{7}$ showed that 70\% of hamstring injuries in elite football players occur during high-speed running and the rest with stretching, sliding, twisting, turning, passing, jumping and overuse. Their numbers are close to ours based on the number of players reported to us by the medical teams, $72 \%$ of the injuries were high-speed running and 28\% stretching-injuries, occurring during, for example, high kicking, sliding tackle and split motions. Establishing type of injury provides essential prognostic information since stretching-type of injury has, on the average, $84 \%$ longer times (59 vs 32 days) to return than sprinting-type of injury in the present study. Other measurements with similar prognostic value, that is, prolonging or shortening the time to return, are position of peak pain upon palpation and position of the proximal pole of the oedema in relation the ischial tuberosity as well as oedema length upon MRI. Correlation analysis showed that the shorter the distance to tuber and the longer length of the oedema the longer the time to return. The latter two findings are in accordance with earlier studies. 42021 Interestingly, these effects on time to return were all independent of the two rehabilitation protocols applied here. So, there seems to be room for developing exercises that are more specific with respect to injury type and location.

\section{MRI-negative injuries}

In our study, 11 players showed typical sprinting-injury, but had no signs of acute hamstring injury upon MRI investigation. The clinical examination, performed within 2 days, showed all typical signs of acute hamstring injury, for example, distinct palpation pain; pain provoked by isometric contraction of the hamstrings and reduced straight leg raise performance, compared with the uninjured leg. Possible explanations for this discrepancy could be that the structural defect is below the detection limit of the MRI or radiologist, the oedema is limited and cleared away within the 5 days before MRI, or spine-related and/or neuromuscular disorders have provoked the acute 
symptoms. $^{7}{ }^{22}$ After undergoing the L-protocol (4 of the 11 players did not perform the L-protocol since they returned within 5 days after injury occurrence), the time to return (average 6 days) for the MRI-negative group was clearly the shortest for all groups investigated here. This is in accordance with earlier studies demonstrating that MRI-negative cases have better prognosis for recovery than those showing injury signs on MRI. $^{7}$ This finding also points out the importance of performing an MRI, not least to identify the MRI-negative hamstring injuries with expected short times to return.

\section{Reinjuries: Askling H-test}

In this study only one reinjury occurred among the 75 players $(0.8 \%)$ during the 12 months follow-up. This is a considerably lower number than the recurrence rates of $12-25 \%$ earlier reported for European football. ${ }^{7} 24{ }^{25}$ There may be several reasons for this. One could be that the rehabilitation protocols were more rigorous and intensive than previous ones. Another might be the introduction of the Askling H-test. Notably, this test must not be performed before all clinical tests at the end of rehabilitation, including those of passive flexibility, indicate complete recovery. Absence of any signs of insecurity is required before the player is allowed to return to full-team training or match. It is not unlikely that the recurrence rate would have been higher had these 40 players been allowed to return, on the average, a week earlier.

\section{Strengths and weaknesses}

The material was large and homogeneous compared with other training studies. The recruitment was entirely based on the willingness of the clubs to report injuries, thus beyond our control. One of the authors (CMA) was responsible for supervising all players' rehabilitation protocols once a week and also for performing the clinical examinations and the Askling $\mathrm{H}$-test. This provided consistency for instructions, examinations and testing. However, it prevented blinding and increased the risk of bias. To decrease bias an independent, blinded test leader had to verify absence of clinical injury signs before the Askling $\mathrm{H}$-test. Furthermore, the performance in this test was judged by the player in terms of absence of insecurity. Lastly, it deserves pointing out that the material consisted of elite football players, eager to perform well and return to play as soon as possible.

\section{CONCLUSION}

A rehabilitation protocol consisting of mainly lengthening type of exercises is more effective than a conventional protocol in promoting return to elite football after acute hamstring injury. On this basis, it is recommended that hamstring injury rehabilitation protocols should be preferentially based on strength and flexibility exercises that primarily involve exercises with high loads at long muscle-tendon lengths. Further studies are needed to verify the possible role of applying the Askling $\mathrm{H}$-test to reduce the commonly high rate of recurrence of hamstring injury (secondary prevention).

\section{What are the new findings?}

- A rehabilitation protocol consisting of mainly lengthening type of exercises is more effective than a conventional protocol in promoting return to elite football after different types of acute hamstring injuries.
How might it impact clinical practice in the near future?

- Improve rehabilitation efficiency after acute hamstring injury by using protocols with lengthening exercises.

- Improve prognosis by determining injury type and using palpation and MRI to establish injury pain, location and size.

Acknowledgements The authors thank the medical staff of Swedish elite football clubs, who sent players to be included in the study. The authors also thank Olga Tarassova, Swedish School of Sport and Health Sciences, Hans Larsson, Sabbatsberg Sjukhus, Klas Östberg, Solnakliniken, and Ulf Gustafsson, FeelGood, for their skilful contributions to this research. The Swedish Centre for Sport Research is gratefully acknowledged for financial support.

Contributors CMA, MT and AT designed the study, monitored data collection, analysed the data and drafted and revised the paper.

Competing interests None.

Patient consent Obtained.

Ethics approval Karolinska Institutet.

Provenance and peer review Not commissioned; externally peer reviewed.

\section{REFERENCES}

1 Ekstrand J, Hägglund M, Waldén M. Epidemiology of muscle injuries in professional football. Am J Sports Med 2011;13:1226-32.

2 Hägglund $M$, Waldén $M$, Ekstrand J. Injuries among male and female elite football players. Scand J Med Sci Sports 2009;19:819-29.

3 Askling C, Saartok T, Thorstensson A. Type of acute hamstring strain affects flexibility, strength, and time to return to pre-injury level. Br J Sports Med 2006;40:40-4.

4 Askling C, Tengvar M, Saartok T, et al. Acute first-time hamstring strains during high-speed running. A longitudinal study including clinical and magnetic resonance imaging findings. Am J Sports Med 2007a;35:197-206.

5 Askling C, Tengvar M, Saartok T, et al. Acute first-time hamstring strains during slow-speed stretching. Clinical, magnetic resonance imaging, and recovery characteristics. Am J Sports Med 2007b;35:1716-24.

6 Askling C, Tengvar M, Saartok T, et al. Proximal hamstring strains of stretching type in different sports. Injury situations, clinical and magnetic resonance characteristics, and return to sport. Am J Sports Med 2008;36:1799-804.

7 Ekstrand J, Jeremiah $\mathrm{HC}$, Waldén $\mathrm{M}$, et al. Hamstring muscle injuries in professional football: the correlation of MRI findings with return to play. Br J Sports Med 2012;46:112-17.

8 Hägglund $M$, Waldén $M$, Ekstrand J. Previous injury as a risk factor for injury in elite football: a prospective study over two consecutive seasons. Br J Sports Med 2006;40:767-72.

9 Petersen J, Thorborg K, Bachmann Nielsen M, et al. Preventive effect of eccentric training on acute hamstring injuries in men's soccer. Am J Sports Med 2011;39:2296-303.

10 Sherry MA, Best TM. A compariason of 2 rehabilitation programs in the treatment of acute hamstring strains. J Orthop Sports Phys Ther 2004;34:116-25.

11 Croisier JL, Ganteaume S, Binet J, et al. Strength imbalances and prevention of hamstring injury in professional soccer players: a prospective study. Am J Sports Med 2008;36:1469-75.

12 Heiderscheidt BC, Sherry MA, Silder A, et al. Hamstring strain injuries: recommendations for diagnosis, rehabilitation, and injury prevention. J Orthop Sports Phys Ther 2010;40:67-81.

13 Chumanov ES, Heiderscheit BC, Thelen DG. The effect of speed and influence of individual muscles on hamstring mechanics during the swing phase of sprinting. J Biomech 2007;40:3555-62.

14 Schache AG, Dorn TW, Blanch PD, et al. Mechanics of the Human Hamstring Muscles during Sprinting. Med Sci Sports Exerc 2012;44:647-58.

15 Askling CM, Nilsson J, Thorstensson A. A new hamstring test to complement the common clinical examination before return to sport after injury. Knee Surg Sports Traumatol Arthrosc 2010;18:1798-803.

16 Brockett $\mathrm{CL}$, Morgan DL, Proske U. Predicting hamstring strain injury in elite athletes. Med Sci Sports Exerc 2004;36:379-87.

17 Schmitt B, Tyler T, McHugh M. Hamstring injury rehabilitation and prevention of re-injury using lengthened state eccentric training: a new concept. Int I Sports Med 2012;7:333-41. 
18 Sole G, Milosavljevic S, Nicholson $\mathrm{H}$, et al. Selective strength loss and decreased muscle activity in hamstring injury. J Orthop Sports Phys Ther 2011;41:

354-63.

19 Malliaropoulos N, Mendiguchia J, Pehlivanidis $\mathrm{H}$, et al. Hamstring exercises for track and field athletes: injury and exercise biomechanics, and possible implications for exercise selection and primary prevention. Br J Sports Med 2012;46:846-51.

20 Schneider-Kolsky ME, Hoving JL, Warren P, et al. A comparison between clinical assessment and magnetic resonance imaging of acute hamstring injuries. Am J Sports Med 2006:34:1008-15.

21 Slavotinek JP, Verrall GM, Fon GT. Hamstring injury in athletes: using MR imaging measurements to compare extent of muscle injury with amount of time lost from competition. Am J Roentgenol 2002;179:

1621-8.

22 Orchard JW, Farhart $\mathrm{P}$, Leopold C. Lumbar spine region pathology and hamstring and calf injuries in athletes: is there a connection? Br J Sports Med 2004;38:502-4.

23 Verall GM, Slavotinek JP, Barnes PG, et al. Clinical risk factors for hamstring muscle strain injury: a prospective study with correlation of injury by magnetic resonance imaging. Br J Sports Med 2001;35:435-9.

24 Petersen J, Thorborg K, Nielsen MB, et al. Acute hamstring injuries in Danish elite football: a 12-month prospective registration study among 374 players. Scand J Med Sci Sports 2010:20:588-92.

25 Woods C, Hawkins RD, Maltby S, et al. The Football Association Medical Research Programme: an audit of injuries in professional football—analysis of hamstring injuries. Br J Sports Med 2004;38:36-41. 